\title{
A INTERPRETAÇÃO COMERCIAL COMO OFÍCIO: UM ESTUDO PILOTO PARA MELHOR COMPREENSÃO DA EXPERIÊNCIA BRASILEIRA
}

\author{
Anelise Gondar
}

\section{Introdução}

Ainda que a sociedade moderna esteja testemunhando o crescimento cada vez mais notável das possibilidades de comunicação direta entre pessoas de diferentes culturas e línguas através do melhor acesso a recursos tecnológicos, a presença do intérprete "humano" parece continuar exercendo papel imprescindível nas plenárias e encontros de membros de instituições internacionais, em negociações de acordos comerciais, no apaziguamento de conflitos e no tratamento pessoal entre diferentes pares. A função do intérprete é, portanto, eminentemente social e, com a globalização e o aumento exponencial da mobilidade humana pelo globo, a interpretação precisa atender aos mais variados contextos sociais e culturais.

Assim, com vistas a entender melhor alguns desses diferentes contextos, o foco deste trabalho será o profissional da interpretação chamada comercial, o profissional habilitado por concurso público a exercer a função de intérprete em paralelo à atividade de tradução juramentada. O presente trabalho tem como objetivo primordial apresentar uma abordagem exploratória ao tema, buscando elucidar algumas atribuições do intérprete comercial baseadas em lei e, do ponto de vista analítico, procurando apresentar subsídio metodológico para uma aproximação ao trabalho desempenhado - e desafios enfrentados - pelo intérprete comercial no Brasil, a exemplo do contexto da cidade do Rio de Janeiro ${ }^{1}$. Para tanto, foi realizada uma entrevista-piloto com base em questionário semiestruturado, que visou à obtenção de dados objetivando elucidar diferentes aspectos da atividade do intérprete comercial. A análise mais aprofundada, a partir da ampla consulta a muitos intérpretes comerciais, mesmo que apenas no contexto do estado do Rio de Janeiro, extrapolaria o escopo temporal da realização deste trabalho. Desta forma, a literatura acadêmica, o material documental e entrevista-piloto cumprirão o papel de fornecer uma aproximação exploratória desse campo profissional.

\footnotetext{
${ }^{1}$ A pesquisa também tem como justificativa a pouca referência a esse tipo de interpretação no curso de pós-graduação em Formação de Intérpretes de Conferência da PUC-Rio - principal local de formação de Intérpretes no Rio de Janeiro e local de formação da autora do artigo.
} 
GONDAR - A interpretação comercial como ofício...

Entende-se que é necessária a replicação do estudo com um número de casos $(\mathrm{N})$ maior para que os resultados sejam representativos da situação do intérprete comercial no Rio de Janeiro e possa assim ser comparável no âmbito nacional e internacional. O estudopiloto cumpre assim a sua função de pavimentar metodologicamente o caminho para um estudo quantitativa e qualitativamente representativo.

\section{Interpretação como prática situada e subsídios teóricos para a abordagem da interpretação comercial}

A interpretação é um ofício multifacetado e a existência e utilização de um tipo ou outro de interpretação tem sido produto da necessidade e da evolução histórica do emprego do intérprete nos mais variados contextos. É necessário fazer a distinção entre as modalidades de interpretação e tipos situacionais de interpretação ou o que Angelelli (2001, p. 88) chamará provocativamente de situated practices ${ }^{2}$ ou práticas situadas. As modalidades ensinadas nos ambientes de formação de intérpretes (a interpretação simultânea, a interpretação consecutiva e a interpretação sussurrada) são, em larga medida, empregadas na prática da interpretação ${ }^{3}$. O conhecimento dessas três modalidades de interpretação faz parte da formação básica do intérprete e estas podem ser consideradas formas de interpretação comuns no mercado institucional e privado. No entanto, há tipos de interpretação que parecem ser especialmente situados. Nestes, a prática do intérprete é condicionada mais fortemente tanto do ponto de vista do conteúdo como do ato discursivo. E nestes, o intérprete é visto e, por vezes, é tido como parte, de fato, integrante da comunicação entre as partes. Esse é o caso da interpretação em tribunais, por exemplo, em inúmeros países e também da chamada interpretação

\footnotetext{
${ }^{2} \mathrm{O}$ reconhecimento de que a atuação do intérprete se dá em "práticas situadas" evidencia a convicção da autora de que a prática da interpretação não ocorre "no vácuo". Isso implica afirmar que em todas as situações, ainda que em diferentes graus, a voz do intérprete se faz presente e é parte integrante do ato do discurso, ainda que o intérprete - especialmente o "de conferências" - queira ser apenas um canal neutro de transmissão da mensagem.

${ }^{3} \mathrm{Na}$ interpretação simultânea a emissão original do orador é simultaneamente vertida pelo intérprete para outra língua. Para tanto, faz-se necessário o uso de aparelhagem de som que permita ao intérprete receber a emissão na língua de partida através de fones de ouvido e produzir o discurso vertido para a língua de chegada através de microfones. Depreende-se a partir do nome da modalidade que as atividades de recepção do discurso na língua de partida e produção de uma versão deste em língua de chegada ocorrem quase simultaneamente. Na interpretação consecutiva, que prescinde de equipamento de som com receptores individuais para os ouvintes, ao molde da interpretação simultânea, o intérprete ouve a mensagem na língua original, tomando notas e depois realiza a interpretação do trecho ouvido. Há, portanto, pausas durante a emissão do texto do orador original. Na interpretação sussurrada, o intérprete realiza a interpretação simultaneamente, sem que o orador faça pausas, para poucos ouvintes e também sem o auxílio do equipamento de som.
} 
GONDAR - A interpretação comercial como ofício...

comunitária ${ }^{4}$. O campo profissional da interpretação comercial é diverso e tem interface prática com a ideia de interpretação comunitária no contexto internacional por abarcar a atuação em ambientes jurídicos (tribunais, delegacias...). De fato, o intérprete comercial é aquele profissional que, credenciado de fé pública, não apenas auxilia na comunicação entre partes interessadas, mas também responde à autoridade estatal e à sociedade civil pelos serviços de tradução e interpretação que presta. A interpretação em juízo pode ser identificada pela sua finalidade pública/oficial (questões civis, como casamentos) e implica na relação entre duas partes mediadas por uma instituição pública (como é o caso dos casamentos) ou entre uma parte e uma instituição pública (em julgamentos, por ex.). O intérprete em juízo, ou comercial, está vinculado ao Poder público porque atende às prerrogativas estabelecidas oficialmente para o exercício do ofício. No entanto, não representa a posição do governo quando solicitado a realizar a mediação linguísticocultural entre a(s) parte(s) e a instituição pública. Vê-se que a denominação "Intérprete Comercial" e as atribuições inerentes ao ofício abarcam elementos específicos, pouco explorados ainda na literatura especializada no Brasil. De fato, o "Intérprete Comercial" é o profissional solicitado para fazer interpretações juramentadas em todas as instâncias da vida pública em que essa atribuição se faz necessária. Sua função encontra interfaces com o que se conhece no Brasil como interpretação judicial (ou "interpretação em tribunais") e interpretação médica 5 .

Ainda que a interpretação face a face com o objetivo de possibilitar a comunicação entre duas partes esteja entre as atividades mais antigas no mundo, verifica-se que o estudo da interpretação fora do ambiente de conferências permaneceu por muito tempo à margem dos estudos tradicionais da atividade de interpretação (Angelelli, 2001; Pöchhacker, 1999; 2006) ${ }^{6}$. A interpretação fora dos contextos de

\footnotetext{
4 Mikkelson (1996) afirma que "community interpreters primarily serve to ensure access to public services, and are therefore likely to work in institutional settings".
}

5 Também há interfaces com o que se conhece em outros contextos como "community interpreting”,
interpretação comunitária, envolvendo questões entre minorias étnicas ou imigrantes e o Estado de
acolhida em seus vários setores: escolar, na área da saúde e na área jurídica, por exemplo. Em alguns
desses contextos, a interpretação é revestida de caráter oficial e também de legitimidade jurídica.
6 De fato, a interpretação emerge como campo de estudo a partir de meados do século XX, quando as
condições históricas singulares ocasionaram o surgimento da interpretação simultânea através do uso da
tecnologia de som e, consequentemente, possibilitaram a expansão deste tipo de atuação profissional. Este
campo profissional começa a se fortalecer como foco de estudos acadêmico-científicos com o surgimento 
conferências, no entanto, é uma das atividades mais antigas ligadas à comunicação intercultural. Esse tipo de interpretação ocorre em contextos chamados pela literatura de intrassociais. São contextos em que se necessita de interpretação para aceder a uma instância oficial ou a algum serviço em determinado país. Ou seja, um contexto localizado como no caso de um paciente, réu ou negociador contratual estrangeiro que necessita compreender e se comunicar no contexto cultural específico de um determinado país, situação bastante distinta do contexto de "conferências". A interpretação nesses contextos tem um objetivo imediato de geração de canais de comunicação para o bem-estar das partes envolvidas. É possível identificar aí um caráter específico da atividade de interpretação: a habilidade de reunir pessoas, em situações-limite por vezes, com o objetivo de produzir resultados em negociações ou processos transacionais, diferente da transmissão de conhecimento, frequente nas situações de conferências. Os países em que essa atuação encontra eco mais forte na literatura acadêmica são justamente os países que têm um passado (ou presente) multicultural e que assumiram, com menor ou maior dificuldade, os desafios que advém da heterogeneidade de suas populações ${ }^{7}$.

Ainda que em distintos campos profissionais, os intérpretes comerciais, comunitários e de conferências têm em comum o seu objetivo final: lidar com uma atividade essencialmente complexa que consiste da tradução de mundos ou, nas palavras de Milton e De Sena França (2001, p. 4), "to facilitate a meeting of minds" (facilitar o encontro de ideias). Os desafios na interpretação comercial parecem ser similares aos da interpretação de conferências: a natureza complexa da atividade mental, a importância da precisão e verossimilhança no discurso e as poucas possibilidades de educação formal na área seguem sendo grandes questões comuns ao desempenho da profissão. A existência de algumas compatibilidades entre as interpretações comercial e de conferências, bem como a insuficiência de estudos referentes às realidades específicas do intérprete comercial no contexto brasileiro,

do curso de interpretação em nível universitário em diversos países e, portanto, a partir da reflexão acadêmica sobre a atividade de interpretação (para detalhes, ver Angelelli, 2001).

${ }^{7}$ Um trabalho referenciado por Queiroz (2011) na área da interpretação fora do contexto clássico das conferências é o de Novais Néto (2009). O autor descreve e analisa a atividade de intérpretes comerciais e também de intérpretes ad hoc (pessoas com diferentes níveis de proficiência linguística convidadas para fornecer ajuda na comunicação intercultural) no estado de Roraima. Como Roraima é um estado fronteiriço à República Bolivariana da Venezuela a Oeste e à República Cooperativa da Guiana a Leste, surgem frequentemente questões legais e criminais que envolvem estrangeiros e requerem assim a presença de intérpretes comerciais ou ad hoc. 
justificam portanto este estudo preliminar. A aproximação a essa área de atuação dá-se pela hipótese de que o ofício de intérprete comercial impõe diferentes desafios ao profissional em comparação ao intérprete de conferências. Se considerarmos essa diferença, o que então poderia caracterizar a atividade da interpretação comercial? A sua análise emerge dos seguintes critérios:

Contexto de interação comunicativa - o intérprete comercial atua em situações de mediação comunicativa entre partes num contexto comunicativo privado ${ }^{8}$, portanto atua em situações em que o discurso é temporalmente mais curto do que um monólogo em conferência, por ex., e igualmente complexo;

Contexto de trabalho (ou work setting ${ }^{9}$ ) - do ponto de vista da condição e do local de trabalho, identifica-se que a atuação do intérprete comercial pode se dar em qualquer condição e lugar, frequentemente sem o uso de equipamento de som que seria considerado fundamental tanto para o trabalho quanto para o desempenho do intérprete de conferências;

Motivação - frequentemente a interpretação comercial emerge de uma necessidade comunicativa que envolve uma relação de poder assimétrica entre partes (já que em muitos casos o intérprete mediará a interação do cliente com uma instituição oficial, como no ambiente dos tribunais) ou uma relação simétrica entre as partes à sombra do Estado (como é o caso de negociações contratuais entre partes que exigem posterior formalização por meio de instituições do Estado).

Os critérios estabelecidos emergem da consulta à literatura (ver Angelelli, 2001; Queiroz, 2011) e da observação não-sistemática do campo da interpretação no Rio de Janeiro. Portanto, permanece necessário acessar os critérios elencados em análise contrastiva com dados empíricos obtidos através de fontes documentais e entrevistas a intérpretes que atuam nesse ramo.

\footnotetext{
${ }^{8}$ Como elemento de comparação, a literatura aponta a atividade do intérprete de conferências, cuja atuação se dá em meio a público(s) e, portanto, teria formato menos dialógico. Essa característica rende ao intérprete de conferências uma outra relação com a transposição da fala de uma língua para a outra se comparado ao intérprete que media uma conversa.

${ }^{9}$ Angelelli (2001) discorre de forma mais aprofundada acerca do papel do intérprete em suas diferentes áreas de atuação. Em sua pesquisa, atenção especial é dada às condições de atuação, incluindo o local, o momento da interpretação e as questões sócio-interacionais que definem o evento (cliente, motivo, por ex.).
} 


\section{Atribuições do intérprete comercial segundo a Junta Comercial do Estado do Rio de Janeiro - análise documental}

A interpretação pública ou comercial é função do tradutor juramentado, função que, no Brasil, é desempenhada por tradutores aprovados em concurso público e que estão devidamente arrolados nos registros das Juntas Comerciais estaduais ${ }^{10}$. A lei que institui o ofício de Tradutor Público e Intérprete Comercial data de 1943 e versa sobre as atribuições, direitos e deveres daquele que, por concurso público, é admitido à listagem de tradutores que dispõem de fé pública para realizar serviços de tradução e interpretação que exijam comprovação reconhecida oficialmente pelo Estado ${ }^{11}$. O "Tradutor Público e Intérprete Comercial" é responsável pela tradução de todo e qualquer documento produzido de forma escrita ou oral que tenha de ser reconhecido e utilizado em repartições ou órgãos públicos ${ }^{12}$.

No capítulo III, o Artigo 17a afirma que é atribuição desse profissional:

Passar certidões, fazer traduções em língua vernácula de todos os livros, documentos e mais papeis escritos em qualquer língua estrangeira, que tiverem de ser apresentados em Juízo ou qualquer repartição pública federal, estadual ou municipal ou entidade mantida, orientada ou fiscalizada pelos poderes públicos (...) (idem).

E no Artigo 17c lemos algo que se refere especialmente ao ofício de intérprete. O "Tradutor Público e Intérprete Comercial” tem a atribuição de:

interpretar e verter verbalmente em língua vulgar, quando também para isso forem nomeados judicialmente, as respostas ou depoimentos dados em Juízo por estrangeiros que não falarem o idioma do país e no mesmo Juízo tenham de ser interrogados como interessados, como testemunhas ou informantes, bem assim, no foro extrajudicial, repartições públicas federais, estaduais ou municipais (idem).

\footnotetext{
10 As Juntas Comerciais são órgãos subordinados aos governos estaduais que prestam serviços de registros para empresas e ao comércio na referida unidade da federação ${ }^{10}$. Estão submetidas, portanto, ao Governador do Estado e, no caso do estado do Rio de Janeiro, à Secretaria de Estado de Desenvolvimento Econômico, Energia, Indústria e Serviços ${ }^{10}$. O ofício de "Tradutor Público e Intérprete Comercial" inscreve-se oficialmente sob a chancela deste órgão, que determina e fiscaliza a atividade de tradução e versão juramentadas, bem como da atividade de interpretação em juízo.

${ }^{11}$ http://www.planalto.gov.br/ccivil_03/decreto/1930-1949/D13609.htm . Acesso em fev. 2013. E documentação encontrada na referência: http://www.jucerja.ri.gov.br/legislacao/deliberacao/Deliberacao_55.pdf

12 Dados obtidos na página: http://www.jucerja.rj.gov.br/instituicao/objetivos.asp . Acesso em fev. 2013
} 
O Intérprete Comercial, portanto, tem amplas atribuições que abrangem tanto negociações comerciais quanto todo o tipo de tramitação que tenha relação direta com o Poder Público ou imprescinda de atestação de veracidade/fidedignidade para fins públicos. As atribuições de um tradutor juramentado envolvem o contato com uma série de documentos como históricos escolares, diplomas, bem como certidões de nascimento e casamento, indispensáveis à vida em sociedades modernas e que, em tempos de fronteiras cada vez mais fluidas entre países, estão cada vez mais sujeitos à tradução. No entanto, que tipo de atividade prática corresponde ao trabalho do Intérprete Comercial? A ida a campo ajuda a lançar luz sobre algumas dessas atividades, como se verá na seção a seguir.

\section{Entrevista-piloto: metodologia e resultados}

\section{Metodologia}

Com o intuito de compreender mais profundamente a atividade da interpretação comercial no contexto específico do estado do Rio de Janeiro, foi conduzida uma entrevista piloto presencial com um profissional da área. Esta teve duração de pouco mais de 1 (uma) hora. O questionário semiestruturado foi disponibilizado à informante com o título de "Roteiro" e foi composto de dez (10) perguntas ${ }^{13}$. O "Roteiro" permitiu que as informações obtidas em toda a entrevista pudessem ser agrupadas de acordo com as seguintes temáticas: (1) função e características da atividade de intérprete comercial, (2) duração da interpretação e características da performance, (3) forma de ingresso na profissão de intérprete comercial, (4) dificuldades no desempenho da profissão (5) nichos ou mercado de atuação e (6) desafios prospectivos para a profissão.

\section{Resultados $^{14}$}

\footnotetext{
13 As perguntas do questionário foram: 1. O que é a interpretação comercial?; 2. Como se deu seu ingresso na profissão de intérprete comercial?; 3. Quais as dificuldades iniciais?; 4. Como é a interpretação comercial no Rio de Janeiro, na sua opinião?; 5. Há um mercado específico ou há espaço para intérpretes ad hoc?; 6. Quais são os pré-requisitos para o exercício da profissão?; 7. Quais as áreas de atuação?; 8. Qual a formação do intérprete comercial?; 9. Como se dá de fato a interpretação? De forma consecutiva/simultânea; 10. Quais os maiores desafios para a profissão nos próximos anos?

14 Resultados mais detalhados para cada uma das temáticas estão disponíveis na monografia de minha autoria intitulada: "Indo além da Interpretação de Conferências: um estudo-piloto da interpretação
} 
É necessário elencar alguns elementos da entrevista que, em face do material documental, fornecem subsídios para um desenho crítico do panorama da interpretação comercial. É possível verificar que a legislação que habilita o Tradutor Público e Intérprete Comercial (TPIC) à função não estabelece atribuições específicas à tradução pública ou à interpretação comercial, nem detalha as atribuições do intérprete comercial, limitando-se apenas a definir a exclusividade na realização de tradução e versão com fé pública no Brasil. Nesse sentido, percebe-se que, em primeiro lugar, seria necessário que houvesse maior definição das atribuições do TPIC, inclusive com a inclusão nominal da "interpretação" no pequeno rol de atribuições práticas relativas à função. De fato, a legislação apenas menciona a função de "intérprete comercial", sem maior definição das atribuições, o que leva à dificuldade na delimitação do escopo e situação de sua atuação bem como das ferramentas necessárias ao desempenho do(a) intérprete. Diante disso, a prática se dá da seguinte forma: o intérprete comercial atua em tribunais e cartórios, realizando a interpretação em juízo de todo o fluxo de comunicação entre as partes envolvidas. O serviço de interpretação é solicitado pela Justiça ou por particulares e, portanto, a instituição pública ou pessoas físicas são os clientes. O intérprete nessas situações atua como estrito mediador linguístico, mas, como observamos na entrevista, pode ser convidado a fornecer percepções próprias durante o contato entre a instituição pública e a parte interessada, quando atua em juízo.

A atuação do intérprete, no entanto, não se limita aos tribunais. Ao contrário, o escopo e a função da interpretação comercial parecem ser bem mais abrangentes, abarcando o setor comercial e empresarial como um todo. A atuação do intérprete nesses casos é similar ao trabalho de interpretação consecutiva realizado pelo intérprete de conferências. Apreendemos da entrevista que, por vezes, o intérprete comercial não dispõe formalmente (i.e. conforme as exigências do concurso público) das ferramentas e técnicas necessárias para desempenhar esse papel. O que, no entanto, o "qualifica" para a função parece ser o credenciamento junto à Junta Comercial, ou seja, a possibilidade de o intérprete em questão poder dar fé aos documentos que resultam das negociações comerciais realizadas verbalmente. Depreende-se que o credenciamento pode ser uma vantagem competitiva frente a outros serviços de interpretação no mercado privado.

comunitária e comercial no Brasil” - Departamento de Letras, PUC-Rio, 2013. Disponível para download em

http://www.academia.edu/5666483/_Linguistics_Indo_alem_da_interpretacao_de_conferencias_um_estu do_piloto_da_interpretacao_comercial_e_comunitaria_no_Brasil. 
É interessante notar que a intérprete comercial entrevistada nunca atuou em contextos que não o ambiente jurídico e empresarial. A intérprete em questão jamais atuou em contexto médico e informou desconhecer intérpretes comerciais que tenham realizado esse tipo de trabalho. Portanto, é possível compreender que a atividade do intérprete comercial o aproxima mais das atividades exercidas pelo intérprete de conferências do que da interpretação comunitária, que é desempenhada em contato com outras instituições públicas, como hospitais, por exemplo. Dada a aproximação funcional entre o intérprete comercial e o intérprete de conferências, surge o problema do treinamento do intérprete comercial para o desempenho da atividade proposta. $\mathrm{O}$ treinamento adequado parece necessário ao desempenho da função, o que facilitaria o trabalho do intérprete e potencializaria a qualidade e o resultado do trabalho.

Por último, faz-se necessário ressaltar a importância do trabalho do intérprete comercial na mediação cultural entre instituição pública e partes interessadas. Depreende-se do relato da intérprete comercial que o intérprete desempenha por vezes papel protagônico, revestido de autoridade conferida pelo credenciamento junto a órgão público, mas também pelo seu papel em relação aos atores envolvidos. Diante dessa inserção do intérprete no ambiente de trabalho, cabe rever questões relacionadas à possibilidade de neutralidade do intérprete no desempenho da atividade de mediação linguística e cultural ${ }^{15}$.

\section{Considerações finais}

A necessidade de comunicação entre diversos atores sociais e em situações as mais variadas tem justificado historicamente o trabalho de interpretação. A interlocução entre sujeitos de diferentes línguas nativas em esferas formais e informais da vida social em vários países exige não apenas a atuação do intérprete em casos de conferências, mas também em tribunais ou em hospitais, por exemplo. A "internacionalização" da vida social leva à seguinte indagação: há interpretação no Brasil fora do escopo das atribuições do intérprete de conferências? Se sim, qual o seu alcance?

$\mathrm{O}$ intuito deste artigo foi fornecer alguns insumos para aprofundar $\mathrm{o}$

\footnotetext{
${ }_{15}$ Para a discussão acerca da neutralidade e agency na prática da interpretação, ver a discussão interessante desenvolvida por Silva, Christiano S.V. em sua dissertação de mestrado intitulada "Questões de poder e ideologia nos estudos e na prática da interpretação" disponível em < $\underline{\text { http://www2.dbd.puc- }}$ rio.br/pergamum/tesesabertas/1112719_2013_completo.pdf > Acesso em ago. 2013.
} 
conhecimento de formas de interlocução para além da interpretação "clássica", de conferências. O artigo teve como objetivo central apresentar uma abordagem exploratória ao tema da interpretação comercial, buscando do ponto de vista teórico alguns aportes acerca do tema na literatura acerca de situated practices, elucidando atribuições do intérprete comercial conforme documentos da Junta Comercial e, do ponto de vista analítico, buscou fornecer subsídio metodológico para uma aproximação ao trabalho do intérprete comercial através da condução de uma entrevista-piloto que pode servir de base para pesquisas futuras. Diante da escassa literatura especializada em interpretação comercial no contexto brasileiro, as conclusões baseiam-se em larga medida na análise documental e material empírico para fornecer insumos com vistas à compreensão do nicho de atuação desse profissional. Dessa forma, sugere caminhos para pesquisas posteriores com a utilização de questionários semiestruturados, a serem aplicados a um número representativo de informantes.

No campo da interpretação comercial, é possível destacar dois elementos a partir da análise documental e da entrevista piloto: em primeiro lugar, a interpretação comercial abarca não apenas o nicho de atuação para o qual há necessidade formal de intérpretes com fé pública, como no caso da interpretação em tribunais. Seu nicho de atuação tem superposições com a atuação do intérprete de conferências por atuar no mercado privado e em situações empresariais. Nesses contextos, a partir da informação obtida na entrevista, é possível que o intérprete comercial seja preferido ao intérprete "comum" pela legitimidade institucional que detém através da certificação da Junta Comercial. Essa questão leva a algumas reflexões: por um lado, podemos perceber que os desafios impostos ao intérprete comercial são os mesmos impostos ao intérprete de conferências que, no contexto brasileiro, trabalha com muita frequência para o mercado empresarial. Pode-se imaginar que a legitimidade institucional de que está imbuída a atividade do intérprete comercial confere a ele vantagem competitiva no mercado privado de interpretação. A entrevista piloto ainda permitiu identificar outro elemento que merece reflexão: o intérprete comercial por vezes é preferido ao intérprete “comum" pelo compromisso profissional, registrado no momento de sua certificação, com a confidencialidade. Pode-se compreender a partir daí que é possível que ainda haja desconhecimento no mercado empresarial acerca do código de conduta de intérpretes de conferências, com os quais intérpretes em treinamento entram em contato durante o período de formação, e que é amplamente reafirmado pelas associações 
nacionais e internacionais de intérpretes ${ }^{16}$. Em segundo lugar, a atuação do intérprete comercial, conforme o estudo aqui desenvolvido, se dá em ambientes diversos e em situações que parecem exigir preparo técnico similar ao do treinamento de intérpretes de conferências através do emprego da modalidade consecutiva com tomada de notas, por exemplo, bem como preparação temática prévia (estudo de terminologia). A preparação para o trabalho, portanto, deveria ser muito similar à do intérprete de conferências, no entanto, o intérprete comercial precisa adquirir essas ferramentas e técnicas de trabalho baseado na compreensão pessoal da necessidade destas, já que verificamos que o concurso público, forma de acesso à certificação para a profissão, frequentemente não afere todas as habilidades específicas nem qualifica o profissional para a prática da interpretação.

A questão da forma de acesso à profissão de intérprete comercial, de fato, impõe desafios às Juntas Comerciais e ao processo e pré-requisitos para a aprovação de Tradutores Públicos e Intérpretes Comerciais (TPIC). O ambiente de trabalho exige que o TPIC tenha conhecimento de técnicas de interpretação e, para tanto, é necessário adequar as exigências do concurso público ao trabalho prático dos profissionais credenciados.

Em suma, o estudo da interpretação comercial no Brasil ainda constitui-se terreno fecundo para o aprofundamento das seguintes questões, entre outras: há diferenças regionais entre as práticas profissionais de intérpretes comerciais no contexto brasileiro? Quais as maiores dificuldades encontradas por esses profissionais, considerando a pesquisa em nível nacional? Qual a percepção que esses profissionais têm acerca da sua prática? Há experiências já realizadas no treinamento de intérpretes comerciais? Quais as abordagens necessárias e quais os efeitos produzidos? Essas e outras questões extrapolam o escopo desse artigo, no entanto são fundamentais para a compreensão dos rumos da interpretação comercial no contexto brasileiro. A partir do estudo aqui descrito, percebe-se a necessidade da abordagem do tema da interpretação comercial inclusive nos cursos de formação de intérpretes de conferências, para conferir maior conhecimento acerca do campo e para ampliar a compreensão da relevância e da multifuncionalidade da atividade da interpretação na contemporaneidade.

\footnotetext{
16 Dentre elas, a Associação Mundial de Intérpretes de Conferência - AIIC e a Associação Profissional de Intérpretes de Conferência - APIC, esta com atuação exclusiva no Brasil.
} 


\section{Referências bibliográficas}

ANGELELLI, Claudia V. Revisiting the Interpreter's Role: a study of conference, court, and medical interpreters in Canada, Mexico, and the United States, Amsterdam/Philadelphia: John Benjamins, 2004, 127p.

DE SENA FRANÇA, L.; MILTON, J., Interpreting in the Community: the Complexity of the Profession. In: International Conference Critical Link 3. Quebec, Canada, 2001, pp. 1-5.

MIKKELSON, Holly. The Professionalization of Community Interpreting In: Global Vision, Proceedings of the 37th Annual Conference of the American Translators Association, Muriel M. Jérôme-O’Keefe, ed., John Benjamins, pub., 1996. Disponível em < http://works.bepress.com/holly_mikkelson/23/> Acesso em jul.2013.

NÉTO, Lourival Novais. O Intérprete de Tribunal no Brasil: peritus peritorum?. Tese de Doutorado. Programa Linguística Aplicada e Estudos da Linguagem. PUC-SP, 2009.

PÖCHHACKER, Franz, 'Getting Organized': The Evolution of Community Interpreting In: Interpreting Vol. 4(1), Amsterdam/Philadelphia: John Benjamins, 1999, pp.125-140.

Going Social? On pathways and paradigms in interpreting studies. In: Pym, Anthony. Sociocultural Aspects of Translating and Interpreting $\square$ : John Benjamins Publishing Company, 2006, pp. 215-232.

QUEIROZ, Mylene. Interpretação Médica no Brasil. Dissertação de Mestrado. PósGraduação em Estudos de Tradução - PGET. Universidade Federal de Santa Catarina, 2011. 